\title{
Processos de intertextualidade na homenagem musical: um estudo sobre Homenagem a Camargo Guarnieri de Almeida Prado
}

\author{
Processes of intertextuality in the musical homage: a study on \\ Homenagem a Camargo Guarnieri by Almeida Prado
}

por Esthefania Ribeiro Campos.

\section{RESUMO}

Este artigo tem como objetivo verificar a ocorrência de processos de intertextualidade na obra para piano Homenagem a Camargo Guarnieri de José Antonio de Almeida Prado (1943-2010), escrita em homenagem a Camargo Guarnieri (1907-1993), com o intuito de oferecer subsídios para a preparação e construção de uma possível interpretação desta obra, levando-se em conta a presença de elementos estilísticos do universo de obras do homenageado. Esta obra foi escrita em 1987, como parte do caderno Homenagem a Camargo Guarnieri, organizado pelo pianista e professor José Eduardo Martins e editado pela ECA/USP. A análise da obra em questão foi realizada tendo por base a teoria da influência musical elaborada por Joseph Straus em seu livro Remaking the Past: Musical Modernism and the Influence of the Tonal Tradition (1990). A análise permitiu verificar a ocorrência de duas categorias de procedimentos composicionais listados por Straus, a Motivicização e a Centralização.

Palavras-chave Homenagem Musical; Música Brasileira Para Piano; Intertextualidade; Almeida Prado; Camargo Guarnieri

\section{ABSTRACT}

This article aims to verify intertextual processes in the piano work Homenagem a Camargo Guarnieri by José Antonio de Almeida Prado (1943-2010), written as a musical tribute to Camargo Guarnieri (1907-1993), in order to provide tools for preparing and building a possible interpretations of this work, taking into consideration the presence of stylistic elements of Guarnieri's works in the music homage. This work was composed in 1987, as part of the collection Homenagem a Camargo Guarnieri, organized by the pianist and professor José Eduardo Martins and published by ECA/USP. This analysis was based on the theory of musical influence, presented by Joseph Straus in his book Remaking the Past: Musical Modernism and the Influence of the Tonal Tradition (1990). The analysis showed the occurrence of two categories os compositional procedures listed by Straus, Motivicization and centralization.

Keywords Musical Homage; Brazilian Music For Piano; Intertextuality; Almeida Prado; Camargo Guarnieri 


\section{Introdução}

0 processo de construção de uma interpretação musical abrange inúmeros aspectos, muitos deles carregados de complexidade. 0 instrumentista, ao se deparar com a preparação de uma nova obra musical, deve tomar uma série de decisões que, ao longo do processo, podem influir no resultado final de sua interpretação. Ferramenta fundamental para a compreensão aprofundada de uma composição, a análise pode lançar luz em questões relevantes para o performer, contribuindo para uma interpretação musical estilisticamente informada. Nesse sentido, este artigo tem por objetivo verificar a ocorrência de processos de intertextualidade na obra Homenagem a Camargo Guarnieri de José Antonio de Almeida Prado (19432010), escrita em homenagem a Camargo Guarnieri (1907-1993), com o intuito de oferecer subsídios para a preparação e construção de uma possível interpretação desta obra, levando-se em conta a presença de elementos estilísticos do universo de obras do homenageado. Guarnieri é considerado um dos maiores compositores brasileiros do século XX, e sua música, na opinião de Aaron Copland, "representa a vigorosa expressão musical do continente latino-americano" (apud MENDONÇA, 2001, p. 401). Homenagem a Camargo Guarnieri, de Almeida Prado, foi escrita em 1987, como parte do caderno Homenagem a Camargo Guarnieri, organizado pelo pianista e professor José Eduardo Martins e editado pela ECA/USP.

A homenagem musical permeia historicamente toda a produção musical ocidental. Em uma parcela significativa das homenagens musicais, o compositor faz uma reutilização de traços estilísticos e idiomáticos de uma ou mais obras do compositor homenageado, parodiando ou evocando sua linguagem musical. Foi tomada como base para o estudo analítico dos traços estilísticos da obra de homenagem a teoria da influência de STRAUS (1990, p. 9), na qual três modelos correntes são caracterizados: "influência da imaturidade" relacionada ao jovem compositor em seus anos de formação; "influência da generosidade" exemplificada pelo compositor que faz uso consciente do estilo musical de outro artista, reinterpretando e incorporando esse material ao seu universo musical; "influência da ansiedade" que descreve o compositor que se vê em conflito ao não conseguir se desvencilhar da presença da música do passado em sua própria criação. Assim, este trabalho buscou bases teóricas e material bibliográfico vasto para fornecer subsídios à análise da homenagem, tendo como finalidade oferecer dados que possam auxiliar o intérprete na concepção da interpretação da obra.

\section{Almeida Prado e Camargo Cuarnieri: breves biografias}

José Antonio Rezende de Almeida Prado nasceu em Santos, no estado de São Paulo, no dia 08 de Fevereiro de 1943, e faleceu em São Paulo, capital, em 21 de Novembro de 2010. Iniciou os estudos de música com Lourdes Joppert, Maria José Oliveira e 
- Maestro italiano Tabarin. Estudou também piano com Dinorah de Carvalho desde 1954, composição com Camargo Guarnieri, o homenageado de sua obra em análise no presente trabalho, e harmonia e contraponto com Osvaldo Lacerda. No ano de 1969, tendo participado do Concurso Internacional da Guanabara, foi contemplado com o Primeiro Lugar ganhando uma bolsa de estudos na França, onde estudou harmonia, contraponto, composição, análise e rítmica com renomados nomes da música erudita contemporânea, como Olivier Messiaen, Nadia Boulanger e Annette Dieudoneé. De volta ao Brasil, assumiu o cargo de Diretor do Conservatório de Cubatão, e em 1975 passou a lecionar Composição, Orquestração, Percepção e Análise na UNICAMP, instituição na qual também defendeu sua tese de doutorado intitulada Cartas Celestes, Uma Uranografia Sonora Geradora de Novos Processos Composicionais, que veio a se tornar uma das mais importantes obras pianísticas do século XX. Seu catálogo de obras possui cerca de 300 obras, é editada no exterior, já ganhou importantes prêmios composicionais entre eles o Primeiro Lugar no X Concurso Francesc Civil de Girona, Espanha, com a Obra Cantata Cantares do Sem Nome e de Partidas, in memoriam a Mirella Pinotti, sobre poemas de Hilda Hilst, em junho de 1986. Além da atividade de educação possuía também um programa na rádio Cultura FM de São Paulo.

Mozart Camargo Guarnieri nasceu em 1907 em Tietê, São Paulo, e começou seus estudos de música bem cedo, em casa com os pais. Em 1923, o pai decidiu mudar-se para a capital a fim de proporcionar melhor formação ao filho, e em 1925, Guarnieri passou a estudar piano com Antonio de Sá Pereira. Alguns anos depois, iniciou os estudos de harmonia, contraponto, orquestração e composição com o maestro Lamberto Baldi. No ano de 1928, conheceu um daqueles que se tornaria um de seus grandes amigos, defensor e divulgador de sua obra, Mário de Andrade, o qual se tornaria também um importante mentor intelectual do músico, então com 21 anos. Dez anos mais tarde, o compositor foi contemplado com bolsa para estudar na França, onde foi aluno de Charles Koechlin e François Rühlmann. Guarnieri foi premiado diversas vezes nos Estados Unidos (classificou-se em segundo lugar em um concurso realizado em Detroit para eleger a Sinfonia das Américas), o que solidificou sua carreira e tornou-se assim o segundo compositor brasileiro mais executado no mundo, superado apenas por Villa-Lobos. Antes de morrer chegou a receber o prêmio Gabriela Mistral de maior compositor das Américas.

\section{A obra}

Homenagem a Camargo Guarnieri, de Almeida Prado, foi escrita a pedido do pianista José Eduardo Martins, à época professor da ECA - USP, por ocasião do octagésimo aniversário do compositor Mozart Camargo Guarnieri. José Eduardo Martins organizava um caderno de homenagens e entrou em contato com vários dos ex-alunos do maestro Guarnieri, convidando-os a participarem da homenagem, e apenas os seguintes retornaram com suas respectivas obras: Almeida Prado, Brenno Blauth, 
Eduardo Escalante, George Olivier Toni, Kilza Setti e Sérgio de Vasconcellos Corrêa. Diferentemente de Vasconcellos Corrêa, por exemplo, que apresenta uma análise de sua peça, explicando seus procedimentos composicionais, na qual aponta o emprego de traços estilísticos da obra de Guarnieri em sua homenagem (esta análise foi posteriormente publicada na revista Brasiliana, em 2005), Almeida Prado não nos oferece uma extensa explicação sobre sua homenagem e como se deu a influência de Guarnieri sobre ela, apenas diz o seguinte: "Para esta peça utilizei somente os sons relativos às letras CAA - GAE contidas no nome Camargo Guarnieri - construindo um pequeno retrato sonoro do grande compositor brasileiro, me inspirando em alguns mecanismos de seus geniais ponteios. Está construída no seguinte esquema formal: ABCB.". Esta nota de Almeida Prado serviu como ponto de partida para nortear a análise intertextual da obra, que se baseia parcialmente em buscar nos ponteios de Guarnieri procedimentos composicionais reinterpretados por Almeida Prado.

Ao longo do trabalho de análise da obra, procurou-se manter em mente o pensamento de Corrêa, que acredita que "o intérprete deve construir a 'sua' performance baseado naquilo que descobriu ao decodificar a obra. A beleza de qualquer 'interpretação' está justamente nos 'achados' de cada intérprete" (CORRÊA, 2010). Essa é uma questão bastante discutida por músicos e pesquisadores da área. Em seu livro Poética Musical em 6 Lições (1996), Stravinsky discorre sobre a dualidade "compositor x intérprete", e nos oferece uma perspectiva interessante sobre 0 assunto. 0 compositor afirma existir dois tipos de músicos instrumentistas: os executantes e os intérpretes, e diz ainda que o executante apenas traduz os sons da partitura; o intérprete traduz os sons com perfeição além de ter um 'amoroso cuidado', o que não significa recompor a música. Para Stravinsky, as idéias de interpretação e execução diferenciam-se pelo fato de a primeira implicar em "limitações impostas ao músico, ou aquelas que este se impõe a si mesmo em sua função própria, que é a de transmitir música ao ouvinte" (STRAVINSKY, 1996, p. 112), e a segunda ser "a estrita realização de um desejo explícito, que não contém nada além do que ele ordena especificamente" (STRAVINSKY, 1996, p. 112). Mais recentemente, Sandra Abdo, em seu artigo Execução/Interpretação musical: uma abordagem filosófica descreve vários pontos de vista a respeito, e alguns se revelaram bastante radicais, tais como o de Benedetto Croce, que diz ser o intérprete apenas um meio para se reevocar fielmente o significado da obra, devendo executá-la tal qual o compositor executaria. Outras, menos radicais, defendem a importância que o intérprete tem para a criação de um sentido da obra musical. Alguns, como Koellreuter, enxergam a interpretação como uma livre tradução da música, pois é na verdade a decodificação de signos, uma ação por assim dizer subjetiva, sem que por isso o intérprete deixe de perceber as relações sonoras criadas pelo compositor. Outra visão, realmente interessante e relevante para o trabalho, é aquela defendida pelos "relativistas moderados", como H.G Gadamer: "o significado original está para sempre perdido no tempo. A compreensão ocorre do ponto de vista do presente e de nada adianta resgatar o passado. Mais precisamente, a compreensão se efetiva como uma 'fusão de horizontes', isto é, passado e presente (autor e intérprete), juntos, constroem, a cada vez, um novo significado" (GADAMER apud ABD0, 2000, p. 17). 


\section{Teoria da Influência Musical}

Joseph Straus, em sua teoria da influência, contextualiza o processo de conceituação da influência artística no início do século XX, uma época em que a música do passado predominou fortemente, como resultado de desenvolvimentos tecnológicos que proporcionaram maior acesso aos mestres clássicos, estando os compositores modernos "mais profundamente imersos na música do passado (incluindo o passado distante) do que as gerações anteriores estiveram" (1990, p.5). Straus divide sua teoria da influência musical em três categorias diferentes, caracterizadas da seguinte maneira: "influência da imaturidade" relacionada ao jovem compositor em seus anos de formação; "influência da generosidade" exemplificada pelo compositor que faz uso consciente do estilo musical de outro artista, reinterpretando e incorporando esse material ao seu universo musical; "influência da ansiedade" que descreve o compositor que se vê em conflito ao não conseguir se desvencilhar da presença da música do passado em sua própria criação. Esta análise se realizará com base na segunda categoria, a "influência da generosidade", que defende que um compositor em sua maturidade sofrerá influência e se reportará a obras anteriores, mas não de forma imatura, e sim em alusões conscientes ou uma homenagem direta, que é o caso da obra analisada neste trabalho.

Ainda em sua teoria da influência, Straus propõe uma categorização das técnicas composicionais utilizadas e compartilhadas pelos compositores do século XX, apesar destes apresentarem diferenças estilísticas superficiais. Essas técnicas são utilizadas para refazer formas anteriores, elementos de estilo, sonoridades entre outras características de obras o passado (p. 17). As categorias são:

1. Motivicização: o conteúdo motívico do trabalho anterior é radicalmente intensificado.

2. Generalização: um motivo de uma obra anterior é reformulado num conjunto de "pitch-class" do qual faz parte numa ordem não determinada. Esse conjunto de "pitch-class" é então empregado na nova obra de acordo com as normas de uso pós-tonal.

3. Marginalização: elementos musicais que são o centro da estrutura da obra anterior são relegados à periferia da nova obra.

4. Centralização: elementos musicais que são periféricos na estrutura anterior movem-se para o centro da nova obra.

5. Compressão: elementos que ocorrem diacronicamente são comprimidos numa figura sincrônica.

6. Fragmentação: elementos que ocorrem juntos na obra anterior são separados na nova obra.

7. Neutralização: elementos musicais tradicionais são riscados de suas funções 
normais, particularmente de seu impulso progressional. A continuidade do progresso é bloqueada.

8. Simetricização: progressões harmônicas orientadas com finalidade tradicional e formas musicais são feitas inversamente ou simetricamente retrógrada, e assim são imobilizadas.

Com base em traços estilísticos da obra para piano de Camargo Guarnieri coletados em artigos e trabalhos acadêmicos e observados nas partituras do compositor, especialmente os Ponteios, procurou-se identificar a maneira como Almeida Prado faz a releitura do estilo musical de Guarnieri em sua homenagem, levando-se em consideração a categorização elaborada por Straus.

\section{A análise}

Conforme exposto anteriormente, a obra Homenagem a Camargo Guarnieri, de Almeida Prado, foi escrita sob encomenda a fim de homenagear Camargo Guarnieri. Alguns pontos devem ser ressaltados para melhor entendimento da obra. A respeito do tema da homenagem, este foi proposto por Martins, organizador do caderno no qual foi publicada a peça, e seguiu um procedimento, conhecido como soggetto cavato, "no qual a composição é baseada num motivo que é construído com a altura equivalente derivada das letras do nome do homenageado" (ROWND, 1990, p. 32). Neste caso, o motivo foi construído com a altura equivalente as letras do sobrenome do homenageado (Exemplo musical 1).

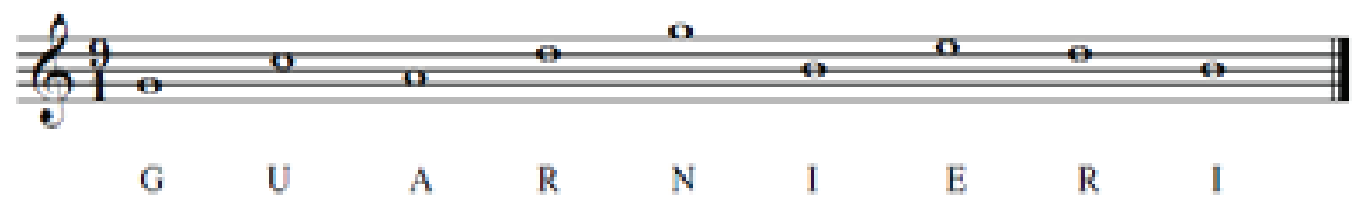

Exemplo musical 1: Tema musical proposto por José Eduardo Martins para compor a homenagem a Guarnieri.

Almeida Prado, entretanto, opta por eleger uma seqüência diferente de alturas, mas ainda assim, relacionadas ao nome do compositor homenageado (Exemplo musical 2):

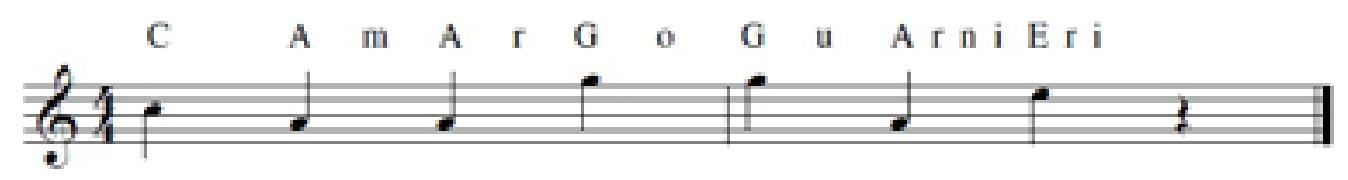

Exemplo musical 2: Tema musical proposto por Almeida Prado para compor sua Homenagem a Camargo Guarnieri. 
Considerando agora a caracterização de Straus podemos citar primeiramente, como uma categoria muito marcante de intertextualidade entre a obra de Camargo Guarnieri e a homenagem de Almeida Prado, a Motivicização, exemplificada pelo uso do ostinato, que a é repetição de uma célula rítmica, melódica ou de alguma outra característica (intervalar, harmônica). As três sessões em que se divide a peça de Almeida Prado possuem algum tipo de ostinato (Exemplos musicais 4, 5 e 6), assim como alguns dos ponteios de Cuarnieri, dentre eles os de número 1, 2, 3, 4, 5, $8,9,12,16,18,22,24$ e 36 (Exemplos musicais 7, 8 e 9).

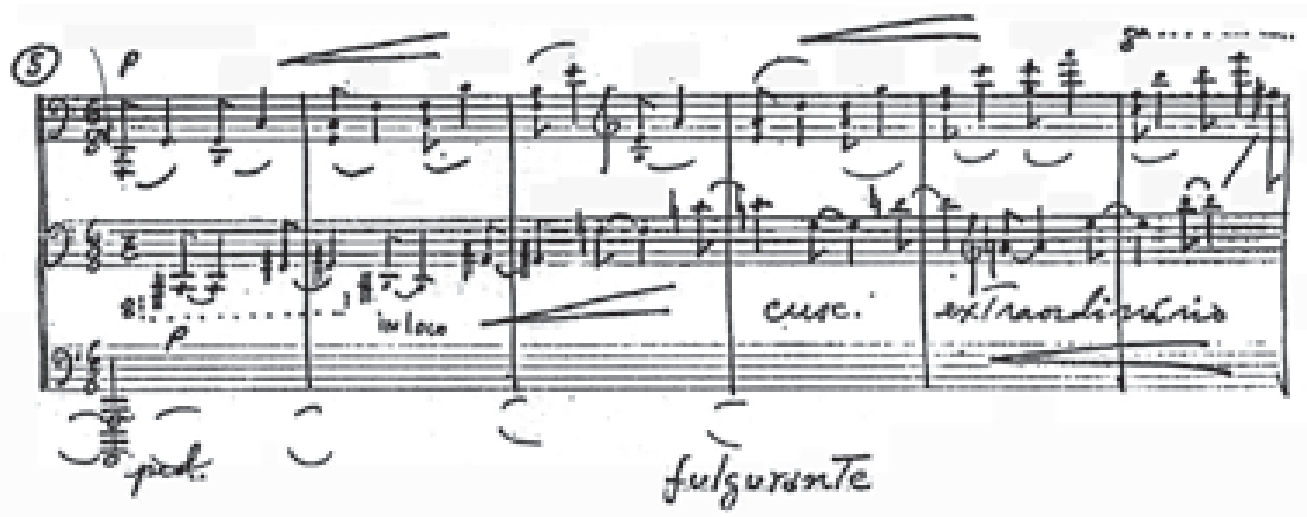

Exemplo musical 4: Ostinato rítmico e intervalar (executado pelas duas mãos) em Homenagem a Camargo Guarnieri de Almeida Prado (Oficinas Gráficas da ECA/USP), c. 5-10.

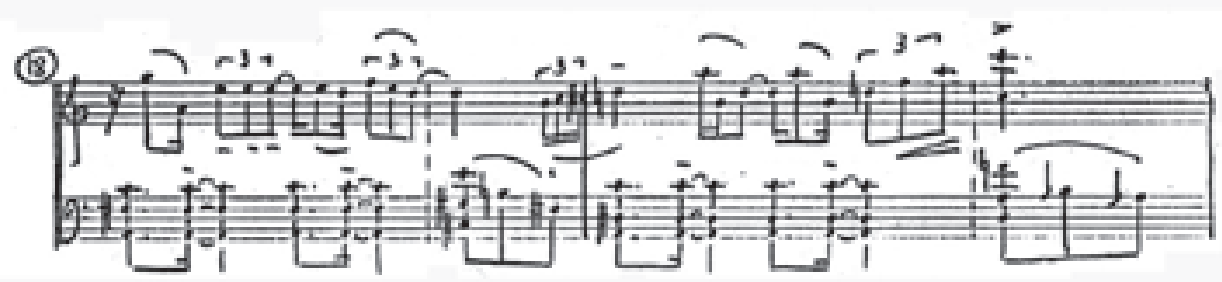

Exemplo musical 5: Ostinato rítmico (executado pela mão esquerda) em Homenagem a Camargo Guarnieri de Almeida Prado (Oficinas Gráficas da ECA/USP), c. 18-19.

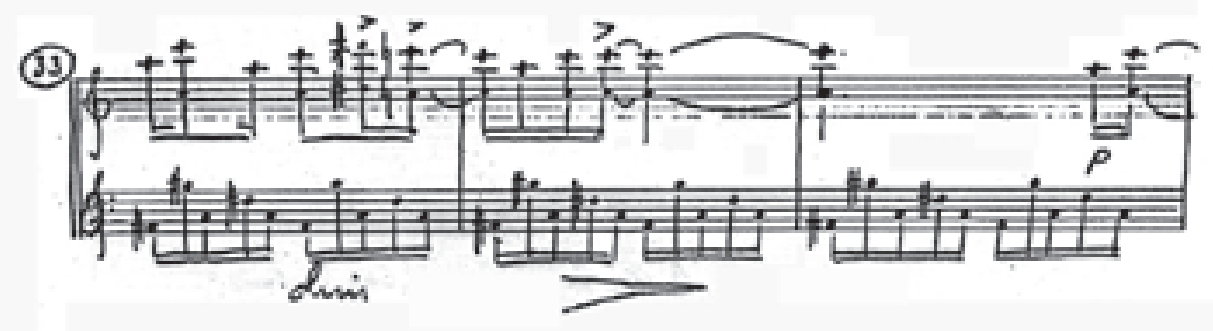

Exemplo musical 6: Ostinato rítmico e intervalar (executado pela mão esquerda) em Homenagem a Camargo Guarnieri de Almeida Prado (Oficinas Gráficas da ECA/USP), c. 33-35. 

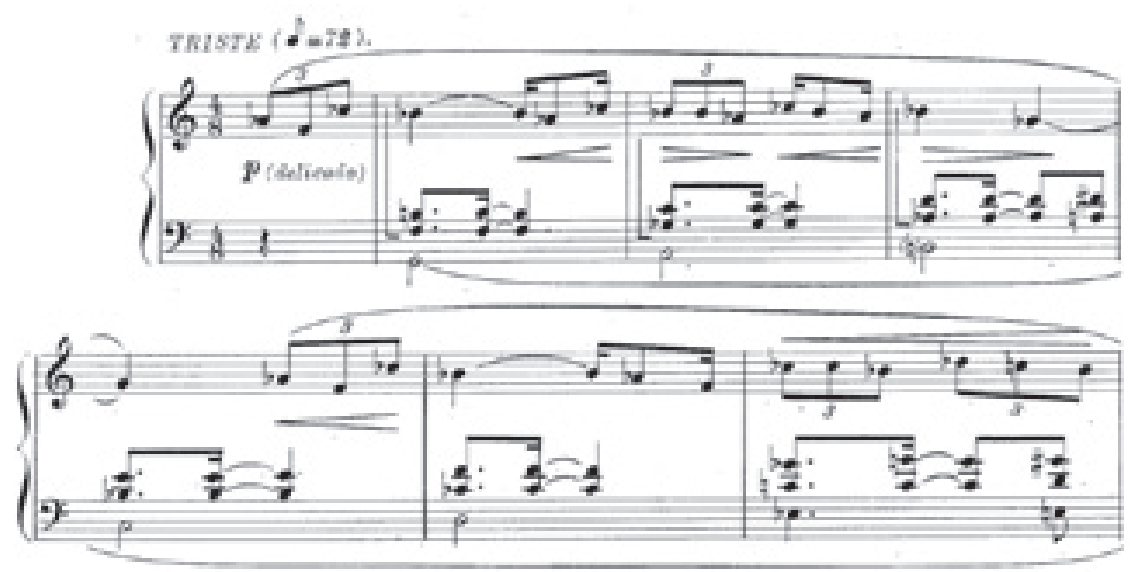

Exemplo musical 7: Ostinato rítmico e intervalar (executado pela mão esquerda) no Ponteio $\mathrm{n}^{\circ} 22$ de Camargo Guarnieri (Ricordi Americana), c. 1-6.

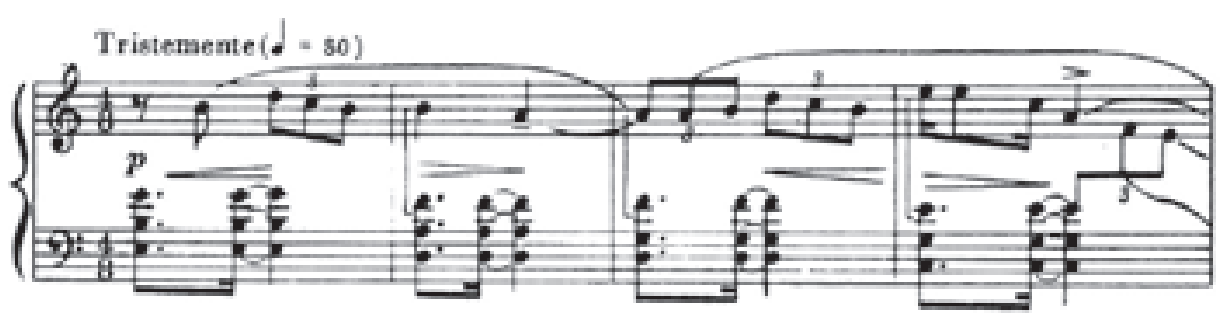

Exemplo musical 8: Ostinato rítmico (executado pela mão esquerda) no Ponteio $n^{\circ} 36$ de Camargo Guarnieri (Ricordi Americana), c. 1-4.
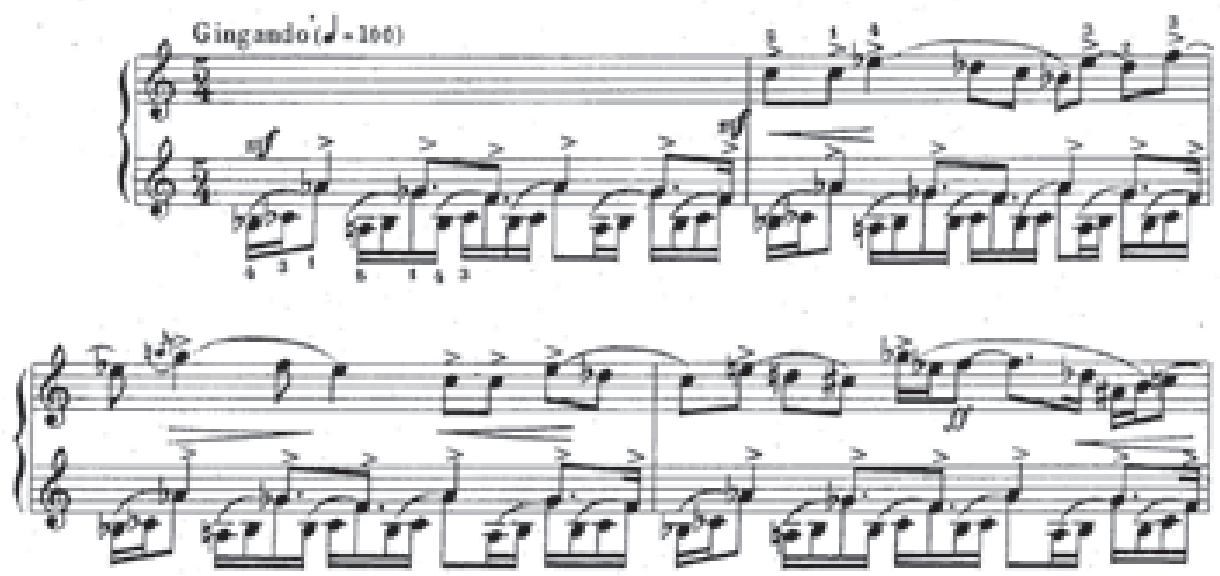

Exemplo musical 9: Ostinato rítmico e intervalar (executado pela mão esquerda) no Ponteio $\mathrm{n}^{\circ} 4$ de Camargo Guarnieri (Ricordi Americana), c. 1-4.

Outra característica que Almeida Prado explora e retira dos Ponteios de Guarnieri é a constante mudança de compasso. A Homenagem a Camargo Guarnieri começa em $7 / 8$, muda para $6 / 8$ no compasso 5 , passa para $11 / 8$ no compasso 17 , na parte C muda para 2/4 e por fim volta a 11/8 no compasso 45 . Uma análise feita por esta 
pesquisadora aponta que em 40 dos 50 Ponteios de Guarnieri ocorre alguma mudança de compasso. Portanto é outra característica que sofre uma motivicização na obra de Almeida Prado.

\begin{tabular}{|c|c|c|c|}
\hline Ponteio & Mudanças de compasso & Ponteio & Mudanças de compasso \\
\hline $\begin{array}{l}\mathrm{N}^{0} 1 \text { Calmo, com pro- } \\
\text { funda saudade }\end{array}$ & $4 / 4,3 / 2$ & $\mathrm{~N}^{0} 26$ Calmo & $3 / 8,3 / 4$ \\
\hline $\mathrm{N}^{0} 2$ Raivoso e ritmado & $5 / 4,4 / 4$ & $\begin{array}{l}\mathrm{N}^{0} 27 \text { Cômodo e expres- } \\
\text { sivo }\end{array}$ & $4 / 8,3 / 8$ \\
\hline $\mathrm{N}^{0} 3$ Dolente & Não há & $\mathrm{N}^{0} 28$ Calmo e sentido & $4 / 4,3 / 4$ \\
\hline $\mathrm{N}^{0}{ }_{4}$ Gingando & $5 / 4,4 / 4$ & $\mathrm{~N}^{0} 29$ Saudoso & $3 / 4,2 / 4,3 / 8$ \\
\hline $\mathrm{N}^{0}{ }_{5}$ Fatigado & Não há & $\mathrm{N}^{0} 30$ Sentido & Não há \\
\hline $\mathrm{N}^{0} 6$ Apaixonado & $3 / 4,5 / 8,2 / 4,3 / 8$ & $\begin{array}{l}\mathrm{N}^{0} 31 \text { Triste, molto ex- } \\
\text { pressivo }\end{array}$ & $4 / 4,3 / 4$ \\
\hline $\mathrm{N}^{0} 7$ Contemplativo & $4 / 4,3 / 4,2 / 4$ & $\begin{array}{l}\mathrm{N}^{0} 32 \text { Com alegria, bem } \\
\text { ritmado }\end{array}$ & $2 / 4,3 / 4$ \\
\hline $\mathrm{N}^{0} 8$ Angustioso & $6 / 8,2 / 4$ & $\mathrm{~N}^{0} 33$ Queixoso & $3 / 4,2 / 4$ \\
\hline $\mathrm{N}^{0} 9$ Fervoroso & $3 / 4,2 / 4$ & $\mathrm{~N}^{0} 34$ Calmo e solene & $4 / 4,3 / 4$ \\
\hline $\mathrm{N}^{0} 10$ Animado & $2 / 4,3 / 4,3 / 8,5 / 8$ & $\mathrm{~N}^{0} 35$ Dengoso & Não há \\
\hline $\begin{array}{l}\mathrm{N}^{0} 11 \text { Triste, molto ex- } \\
\text { pressivo }\end{array}$ & $4 / 4,5 / 4,3 / 2,6 / 8,7 / 8$ & $\mathrm{~N}^{0} 36$ Tristemente & Não há \\
\hline $\mathrm{N}^{0} 12$ Decidido, marcato & $2 / 4,3 / 4$ & $\mathrm{~N}^{0} 37$ Com humor & $6 / 8,9 / 8$ \\
\hline $\mathrm{N}^{0} 13$ Saudoso & $4 / 4,6 / 4$ & $\mathrm{~N}^{0} 38$ Hesitante & Não há \\
\hline $\begin{array}{l}\mathrm{N}^{0} 14 \text { Confiante, can- } \\
\text { tando }\end{array}$ & $2 / 4,3 / 4$ & $\mathrm{~N}^{0} 39$ Dengoso & $4 / 5,3 / 4$ \\
\hline $\mathbf{N}^{0} 15$ Incisivo & $2 / 4,3 / 4,3 / 2,2 / 2$ & $\begin{array}{l}\mathrm{N}^{0} 40 \text { Com moto, bem } \\
\text { legato }\end{array}$ & $3 / 4,4 / 4$ \\
\hline $\begin{array}{l}\mathrm{N}^{0} 16 \text { Tranquilamente, } \\
\text { molto expressivo }\end{array}$ & $2 / 3,3 / 4$ & $\mathrm{~N}^{0} 41$ Tristemente & $4 / 8,3 / 4$ \\
\hline $\mathrm{N}^{0} 17$ Alegre & $2 / 4,3 / 4$ & $\begin{array}{l}\mathrm{N}^{0} 42 \text { Dengoso, mas sem } \\
\text { pressa }\end{array}$ & $2 / 4,3 / 8,3 / 4$ \\
\hline $\mathrm{N}^{0} 18$ Nostálgico & $2 / 4,3 / 4,5 / 8,7 / 8$ & $\mathrm{~N}^{0} 43$ Grandeoso & Não há \\
\hline $\mathrm{N}^{0} 19$ Calmo & $4 / 4,3 / 2$ & $\begin{array}{l}\mathrm{N}^{0} 44 \text { Desconsoado, in- } \\
\text { timo }\end{array}$ & $4 / 4,3 / 4$ \\
\hline $\begin{array}{l}\mathrm{N}^{0} 20 \text { Vagaroso, expres- } \\
\text { sivo }\end{array}$ & $2 / 2,3 / 2,5 / 4$ & $\mathrm{~N}^{0} 45$ Com alegria & $2 / 4,3 / 8,3 / 4,5 / 8$ \\
\hline $\mathbf{N}^{0} 21$ Decidido & $\begin{array}{l}5 / 4,2 / 2,3 / 2,5 / 8,2 / 4, \\
4 / 2,3 / 4,7 / 8\end{array}$ & $\mathrm{~N}^{0} 46$ Íntimo & Não há \\
\hline $\mathrm{N}^{0} 22$ Triste, delicado & $4 / 8,3 / 4$ & $\mathrm{~N}^{0} 47$ Animato & $2 / 4,3 / 4$ \\
\hline $\begin{array}{l}\mathrm{N}^{0} 23 \text { Vigoroso, sempre } \\
\text { seco e arpejado }\end{array}$ & $\begin{array}{l}\text { Alternância entre } 3 / 4 \mathrm{e} \\
4 / 4\end{array}$ & $\mathrm{~N}^{0} 48$ Confidencial & $4 / 4,3 / 2$ \\
\hline $\mathrm{N}^{0} 24$ Tranquilo & Não há & $\mathrm{N}^{0} 49$ Torturado & Não há \\
\hline $\mathbf{N}^{0} 25$ Esperto & $2 / 4,3 / 4$ & $\begin{array}{l}\mathrm{N}^{0} 50 \text { Lentamente } e \\
\text { triste }\end{array}$ & $6 / 8,9 / 8,4 / 8$ \\
\hline
\end{tabular}

Tabela 1: Lista dos Ponteios de Guanieri com indicação das mudanças de compasso.

Temos então uma nova categorização de Straus a ser exemplificada, que é a Centralização. A característica que Almeida Prado escolheu para evidenciar em sua homenagem foi o uso de harmonia modal com coloridos cromáticos para sustentar 
a melodia da parte $B$ da peça, do compasso 17 ao 23 , como pode-se observar no exemplo musical 10:
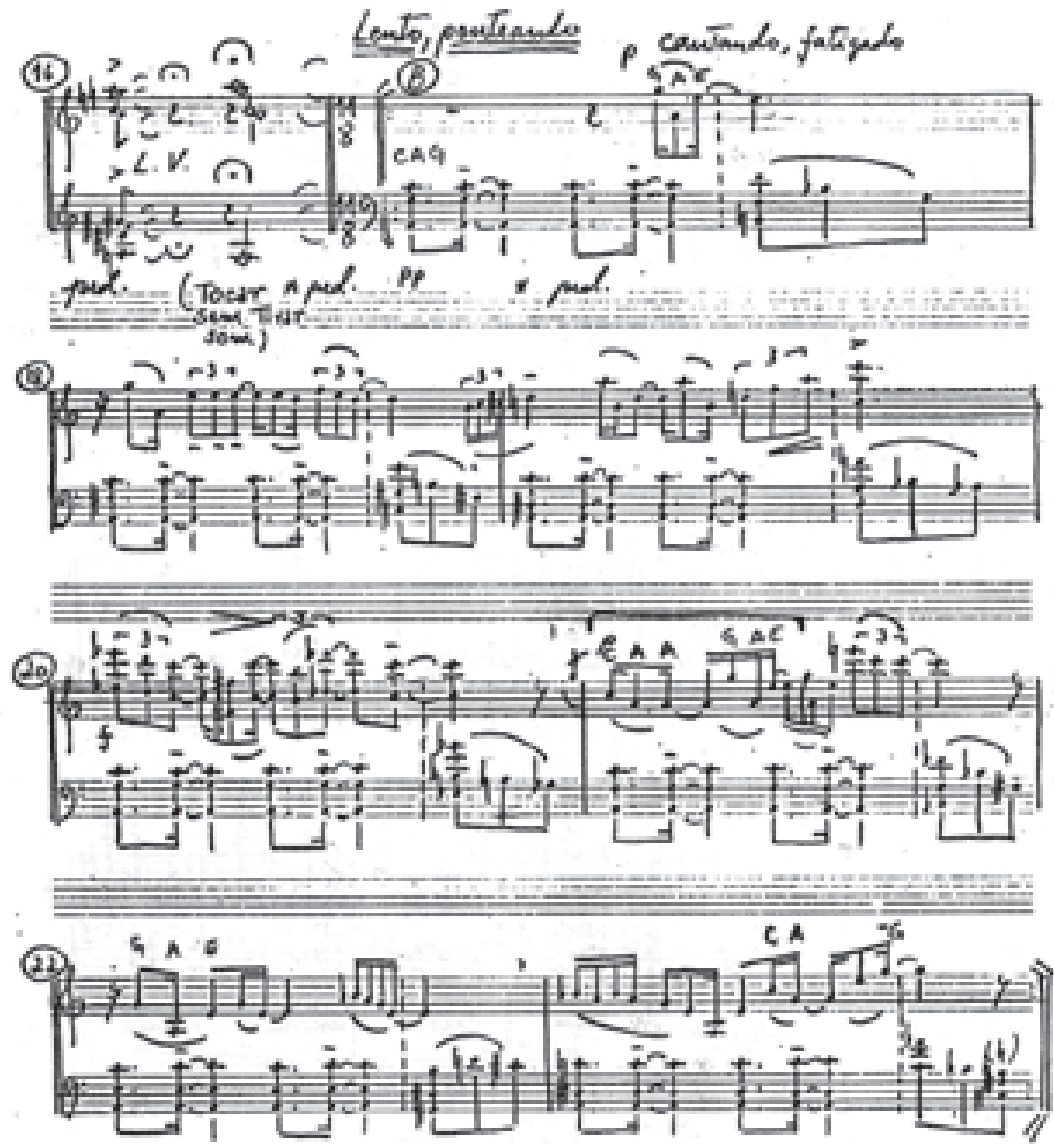

Exemplo musical 10: Homenagem a Camargo Guarnieri de Almeida Prado (Oficinas Gráficas da ECA/USP), C. 16-23.

0 trecho apresentado acima é construído com sonoridades no modo eólio, dórico e mixolídio, resultantes do uso de cromatismo. Nos Ponteios de Guarnieri as melodias lentas aparecem quase sempre numa harmonia modal, nos modos lídio e mixolídio, por exemplo. Em seu livro Camargo Guarnieri: Expressões de uma Vida, Marion Verhaalen comenta que "muitas das melodias [de Guarnieri] possuem orientação modal, não obstante as nuanças cromáticas modificarem os modos e as tonalidades maiores ou menores. Os modos mais usados são o dórico, o lídio, o mixolídio e o modo do nordeste" (VERHAALEN, p. 135, 2001). As melodias de Guarnieri são muitas vezes melodias simples, mas muito expressivas, assim como a melodia de Almeida Prado. Prova da intenção dessa expressividade é a indicação que o compositor coloca no início da parte B: "Lento", "Ponteando e cantando", "fatigado". 


\section{Indicações de caráter do andamento}

Além das categorizações tratadas acima, as indicações de caráter do andamento foi outra semelhança observada durante a pesquisa. Desde o início Guarnieri foi um compositor nacionalista, e quando, em 1928, se encontrou com Mário de Andrade, obteve logo o apoio e amizade daquele que era o maior porta-voz do nacionalismo no Brasil. Nesse primeiro encontro, Mário de Andrade ouviu algumas peças do jovem compositor, e identificou-as logo com suas teorias, e um dos pontos que chamaram a atenção, foi justamente o fato de os subtítulos da Sonatina $n^{0}{ }_{1}$, por exemplo, serem apresentados em português, e não em italiano como de costume (VERHAALEN, 2001, p. 23). Essa característica sobressai muito nos ponteios de Guarnieri: a representação de um sentimento ou caráter no subtítulo da obra: 0 Ponteio $n^{\circ}{ }_{1}$ é indicado "Calmo, com profunda saudade", no nć3 "Dolente", o nć 5 "Fatigado" (os exemplos musicais 7,8 e 9 também ilustram essa prática), e assim por diante, todos eles têm sua representação de um sentimento ou estado emocional. Não somente os ponteios, mas as Sonatinas, os Improvisos e os Momentos também são ótimos exemplos para representar tal característica. Na Homenagem a Camargo Guarnieri podemos identificar no primeiro compasso a indicação "Rude, granítico", já na parte B a indicação "Lento, ponteando" surge para caracterizar a mudança de seções, o mesmo acontece na parte $C$ quando Almeida Prado indica "misterioso, noturnal", além de uma mudança de caráter dentro da própria seção indicada pelas palavras "intenso, avermelhado", e por fim, na volta da seção B, o compositor utiliza as mesmas indicações anteriores.

\section{Conclusão}

0 trabalho de análise de uma obra musical pode servir a inúmeros propósitos, dentre eles um aprofundamento do conhecimento do processo criativo do compositor. Homenagem a Camargo Guarnieri é uma obra criada com o objetivo específico e declarado de prestar homenagem ao compositor Camargo Guarnieri, e para tanto, Almeida Prado lançou mão de procedimentos que podem ser observados à luz da teoria da intertextualidade, ou influência musical. 0 compositor afirma ter tomado como inspiração para sua criação um conjunto de obras de Guarnieri, os Ponteios. Através da análise aqui apresentada, a ocorrência de processos intertextuais foi indubitavelmente verificada. Para tanto, foi utilizado como norteador da análise os escritos sobre a Teoria da Influência de Joseph Straus, que apresenta uma detalhada categorização de ocorrências intertextuais na música.

Tendo em mãos a obra de Almeida Prado e seu breve comentário a respeito da Homenagem, teve início o processo comparativo entre a obra e o conjunto de Ponteios, que levou em consideração a afirmação do compositor de que ele utilizou "alguns dos mecanismos pianísticos de seus [de Camargo Guarnieri] Ponteios", e 
ocorrências listadas na categorização organizada por Straus. Dentre tal categorização, foi possivel verificar o uso da Motivicização e da Centralização. Outra ocorrência de intertextualidade não contemplada pela categorização de Straus também foi observada, que consiste no uso de palavras em português que denotam um sentimento ou estado de espírito para indicar o caráter do andamento.

Devemos citar aqui a importância deste processo investigativo para o processo de aprendizagem que 0 intérprete desenvolve na construção da interpretação de uma obra musical. Espera-se ainda que este estudo tenha contribuído para aprofundar a investigação a respeito da intertextualidade musical, e que sirva como fonte bibliográfica para futuras pesquisas sobre 0 assunto. 


\section{Referências Bibliográficas}

> ABD0, Sandra Neves. Execução/Interpretação musical: uma abordagem filosófica. Belo Horizonte: Per Musi, v.1, 2000, p. 16-24

> CORRÊA, Sérgio Vasconcellos. Caricatura $N^{\circ} 1$ (Homenagem a Camargo Guarnieri). Rio de Janeiro: Brasiliana, n. 21, setembro de 2005, p. 2-6.

> CORRÊA, Sérgio Vasconcellos. Entrevista concedida por correio eletrônico. Mensagem recebida por Esthefânia Ribeiro Campos «tklavier@gmail.com», em $14 / 01 / 2010$.

> GUARNIERI, Mozart Camargo. Studi per Pianoforte. Buenos Aires: Ricordi Americana, 1955

$>$ Ponteios per Pianoforte. Buenos Aires: Ricordi

Americana, 1955 Sonatina $n^{0}$ 1. São Paulo: Ricordi Brasileira, 1958

$>$ Sonatina $n^{0}$ 2. São Paulo: Ricordi Brasileira, 1973

$>$ Sonatina $n^{0}$ 3. New York: Associated Music Publish-

ers, 1945 $>$ . Toccata. São Paulo: Ricordi Brasileira, 1947 $>$ . Valsa $n^{0}$ 9. São Paulo: Ricordi Brasileira, 1958 $>$ . Valsa $n^{\circ}$ 10. São Paulo: Ricordi Brasileira, 1958

> MARTINS, José Eduardo (org.). Homenagem a Camargo Guarnieri: seis peças para piano. São Paulo: Oficinas Gráficas da ECA/USP, 1989.

> MENDONÇA, Belkiss Carneiro de. A obra pianística. In: SILVA, Flávio (org.). Camargo Guarnieri: 0 Tempo e a Música. Rio de Janeiro: Funarte, 2001, p. 401-422.

$>$ ROWND, GARY R: Musical Tombeaux and Hommages for Piano Solo. Lexington: University of Kentucky, 1990 (Tese, Doutorado em Música).

> SILVA, Flávio. (org.). Camargo Guarnieri: o Tempo e a Música. Rio de Janeiro: Funarte, 2001, p.401-422

> STRAUS, Joseph N. Remaking the Past: Musical Modernism and the Influence of the Tonal Tradition. Cambridge, Mass.: Harvard University Press, 1990.

> STRAVINSKY, Igor. A Performance Musical. In: Poética Musical (em 6 lições). Tradução: Luiz Paulo Horta. Rio de Janeiro: Jorge Zahar Ed., 1996 > VERHAALEN, Marion. Camargo Guarnieri: Expressões de uma Vida. São Paulo: EDUSP, 2001. 
Processos de intertextualidade na homenagem musical: um estudo sobre Homenagem a Camargo Guarnieri de Almeida Prado

Esthefania Ribeiro Campos, bacharel em Música/Instrumento-Piano pela UNIRIO. Bolsista IC-UNIRIO em 2010 e 2011.

tklavier@gmail.com

Co-autora: Profa Dra Lúcia Silva Barrenechea, professora no Instituto Villa-Lobos da UNIRIO.

lucia.barrenechea@gmail.com 